\title{
O uso de metodologias ativas de ensino por professores de Ciências nas escolas de
}

\section{Angical - PI}

The use of active teaching methodologies by Science teachers in Angical schools - PI

El uso de metodologías de enseñanza activa por parte de los profesores de Ciencias en las escuelas

Angical - PI

Marciane de Sousa Soares

ORCID: https://orcid.org/0000-0002-0385-7945 Instituto Federal de Ciência e Tecnologia do Piauí, Brasil

E-mail: marcianny10@yahoo.com.br

Tatiane Rodrigues de Moura Mauriz

ORCID: https://orcid.org/0000-0001-7637-8497

Instituto Federal de Ciência e Tecnologia do Piauí, Brasil

E-mail: tatianemoura@ifpi.edu.br

Mariane Cruz Costa Ayres

ORCID: https://orcid.org/0000-0003-1808-5703

Instituto Federal de Ciência e Tecnologia do Piauí, Brasil

E-mail: marianecca@gmail.com

Junielson Soares da Silva

ORCID: https://orcid.org/0000-0003-4872-2355

Instituto Federal de Ciência e Tecnologia do Piauí, Brasil

E-mail: junielsonbio10@gmail.com

Clautina Ribeiro de Moraes da Costa

ORCID: https://orcid.org/0000.0001.7512-4540 Instituto Federal de Ciência e Tecnologia do Piauí, Brasil E-mail: clautina@ifpi.edu.br

Jakson Fernandes Lima

ORCID: https://orcid.org/0000-0001-9759-3188 Instituto Federal de Educação, Ciência e Tecnologia do Ceará, Brasil

E-mail: jaksonfernandeslima@gmail.com

Camila Lavor

ORCID: https://orcid.org/0000-0002-7796-9800 Instituto Federal de Educação, Ciência e Tecnologia do Ceará, Brasil

E-mail: camyllaalavor@gmail.com

Glória Fernandes Lima

ORCID: https://orcid.org/0000-0003-0087-0578

Universidade Estadual do Ceará, Brasil

E-mail: gloriafernandeslima@gmail.com

Diego Filismino Vieira

ORCID: https://orcid.org/0000-0002-9285-3726 Instituto Federal de Ciência e Tecnologia do Ceará, Brasil

E-mail: dffvieira@gmail.com

Luiz Francisco Wemmenson Gonçalves Moura

ORCID: https://orcid.org/0000-0001-5854-6709

Universidade Estadual do Ceará, Brasil

E-mail: wemmenson.moura@uece.br

\begin{abstract}
Resumo
Conforme a Diretriz Curricular de Ensino, o estudo de Ciências tem como objeto de estudo o conhecimento científico, associado às diferentes relações entre os seres humanos com os demais seres vivos, na busca de condições de sobrevivência. Sendo assim, para que esse conhecimento se efetive de fato, o mesmo requer uma relação constante entre teoria e prática proporcionando, através de várias metodologias, a absorção contínua de conhecimento, o presente estudo tem como objetivo descobrir se são, e como são utilizadas as metodologias ativas no ensino de Ciências pelos professores da cidade de Angical - PI. Qual o impacto que ela causa na aprendizagem dos alunos. O presente artigo trata-se de um estudo qualitativo para investigação de metodologias com base no recolhimento de dados, afim de qualificar o ensino de Ciências da Natureza em escolas de Angical do Piauí. O mesmo baseia-se em informações contidas, em paramentos legais como BNCC (Base Nacional Comum Curricular), LDB (Lei de diretrizes e bases), Diretrizes e Parâmetros Curriculares, artigos científicos e em pesquisa de campo por meio de questionários.
\end{abstract}


Para isso foi realizada uma pesquisa de campo e qualitativa. Na qual foi possível perceber a necessidade de alguns professores conhecerem as metodologias ativas de forma a obter maior proveito delas e também de recursos disponíveis para utilizá-las com maior eficiência. Isso também somado à mudança do olhar metodológico na execução das aulas e, até mesmo, na curiosidade de conhecer mais ferramentas e metodologias ativas, apesar de haver grandes desafios em executá-las em salas de aula.

Palavras-chave: Ciências; Metodologias; Conhecimento.

\begin{abstract}
According to the Curriculum Guidelines for Teaching, the study of Sciences has as its object of study the scientific knowledge, associated with the different relationships between human beings and other living beings, in the search for conditions of survival. Therefore, for this knowledge to become effective, it requires a constant relationship between theory and practice providing, through various methodologies, the continuous absorption of knowledge, the present study aims to discover if they are, and how they are used. active methodologies in science teaching by teachers in the city of Angical - PI. What impact does it have on student learning. This article is a qualitative study to investigate methodologies based on data collection, in order to qualify the teaching of Nature Sciences in schools in Angical do Piauí. It is based on information contained, on legal provisions such as BNCC (Common National Curriculum Base), LDB (Law of Guidelines and Bases), Curriculum Guidelines and Parameters, scientific articles and on field research through questionnaires. For this, a field and qualitative research was carried out. In which it was possible to see the need for some teachers to know the active methodologies in order to get more out of them and also the resources available to use them more efficiently. This is also added to the change in the methodological view of the execution of classes and, even, the curiosity to know more active tools and methodologies, although there are major challenges in executing them in classrooms.
\end{abstract}

Keywords: Sciences; Methodologies; Knowledge.

\begin{abstract}
Resumen
Según los Lineamientos del Currículo Docente, el estudio de las Ciencias tiene como objeto de estudio el conocimiento científico, asociado a las diferentes relaciones entre los seres humanos y otros seres vivos, en la búsqueda de condiciones de supervivencia. Por tanto, para que este conocimiento sea efectivo, se requiere una relación constante entre la teoría y la práctica proporcionando, a través de diversas metodologías, la absorción continua de conocimientos, el presente estudio tiene como objetivo descobrir si lo son y cómo se utilizan. Metodologías activas en ciencia docencia por profesores en la ciudad de Angical - PI. ¿Qué impacto tiene en el aprendizaje de los estudiantes? Este artículo es un estudio cualitativo para investigar metodologías basadas en la recolección de datos, con el fin de calificar la enseñanza de las Ciencias Naturales en las escuelas de Angical do Piauí. Se basa en información contenida, en disposiciones legales como BNCC (Common National Curriculum Base), LDB (Law of Guidelines and Bases), Lineamientos y parámetros curriculares, artículos científicos y en investigaciones de campo a través de cuestionarios. Para ello se realizó una investigación de campo y cualitativa. En el cual se pudo ver la necesidad de que algunos docentes conozcan las metodologías activas para sacar más provecho de ellas y también los recursos disponibles para utilizarlas de manera más eficiente. A esto también se suma el cambio en la visión metodológica de la ejecución de clases e, incluso, la curiosidad por conocer herramientas y metodologías más activas, aunque existen grandes retos para ejecutarlas en las aulas.
\end{abstract}

Palabras clave: Ciencias; Metodologías; Conocimiento.

\title{
1. Introdução
}

Ao se ensinar ciências dentro de uma corrente crítico-reflexiva essa ação vai além da mera transmissão de conteúdos produzidos pelos grandes gênios. Nesse sentido, trabalhar os conhecimentos científicos em sala de aula deve ser um caminho em que o estudante se aproprie da construção humana do conhecimento e se sinta parte dessa evolução, tendo o ensino de ciências um caráter histórico e cultural como foco principal da formação científica do estudante (Melo, 2013).

No ensino básico, é necessário que algumas práticas do ensino tradicional sejam deixadas de lado ou sejam melhor aprimoradas considerando, em meio a isso, que as práticas pedagógicas dos professores contribuem de maneira bastante significativa para o conhecimento e a aprendizagem dos alunos, e também em encontro a isso os recursos e elementos utilizados em complemento a contextualização dos assuntos e temas específicos a serem tratados em sala de aula. Diretamente ligado a esse contexto está também a maneira de como o docente está em constante observação de como os alunos conseguem atingir certos conhecimentos e competências de acordo com os métodos e as novas formas de abranger o conteúdo, buscando 
inovar sempre e alcançar cada vez mais um entendimento satisfatório da maioria dos discentes em sala de aula (Gonçalves; Silva; Inácio \& Alves. 2018).

Variações de metodologias de ensino ampliam as possibilidades e vantagens para que os alunos possam reter mais os conteúdos, organizar um pensamento crítico e desenvolver competências para resolver problemas quando comparados à metodologia tradicional. A disciplina de ciências está diretamente ligada aos avanços científicos e diretamente articulada com conhecimentos de diversas disciplinas, tanto no ensino fundamental como no ensino médio. Assim, percebemos a importância de fortalecer a base de conhecimento dos alunos do Ensino Fundamental, Crianças/jovens que necessitam se apropriar destes conhecimentos para viver melhor no ambiente em que vivem. Neste sentido, esta terá que ter oportunidade de explorar o ambiente no qual está inserida para compreender os conteúdos que explicam fenômenos, reações tanto em relação ao ambiente como em relação ao seu organismo e as fragilidades dos organismos (Basílio \& Oliveira, 2016). De acordo com (Lara, Lima, Mendes, Ribeiro \& Padilha. 2019, p. 13):

A prática docente pautada nas teorias sócio-interacionistas e nas metodologias ativas de ensino-aprendizagem promoveram um processo de ensino-aprendizagem pautado na mediação realizada pelo professor entre os sujeitos que aprendem e os objetos ou conteúdos a serem conhecidos.

A palavra metodologia refere-se aos caminhos que o docente utilizará para a realização de suas aulas (Freitag, 2017). O termo metodologia ativa começou a ser utilizado pelo professor inglês R.W. Reavan, na década de 1930, nesses modelos são enfatizados os experimentos de aprendizagem com estímulo ao debate, estudos de caso, raciocínio lógico e atividades que buscam melhorar o relacionamento interpessoal dos estudantes (Morán, 2015).

As metodologias ativas são formas contemporâneas de pensar o ensino, respaldada em um dos princípios da nova Base Nacional Curricular Comum BNCC, que é promoção do aluno como protagonista do seu processo de ensinoaprendizagem, contrariando do modelo tradicional, onde o professor era o único detentor do conhecimento (Oliveira, 2020).

O principal objetivo é estimular o aluno a sair da estagnação, motivando o senso de responsabilidade deste com a construção do seu saber. O papel do professor nesse processo é o de mediador e facilitador, planejando suas aulas baseadas na aprendizagem por problemas e projetos (Barbosa e Moura, 2013). São técnicas que fazem uso de problemas reais complexos do mundo real, com proposito de desenvolver o pensamento crítico e a comunicação (Lara et al., 2019).

Dentro do universo das metodologias ativas temos também a gamificação, que apresenta duas características principais: a utilização de jogos, geralmente ela aumenta o engajamento dos alunos nas atividades, e o processo de ensino aprendizagem torna-se lúdico. A segunda característica é o ranqueamento na entrega das atividades, o professor deve incentivar a competição de forma saudável (Oliveira; Pimentel, 2020).

A sala de aula invertida é um modelo proveniente do modelo híbrido, onde o professor passa uma série de temáticas para os alunos pesquisarem em casa, adquirindo o conhecimento de forma autônoma, e ao retornar para a sala de aula este pode colocar o conhecimento em prática, o professor deve mediar a resolução dos exercícios propostos trazendo novos pontos de vista (Martins, 2021).

Com base no exposto, o presente estudo tem como objetivo descobrir se são, e como são utilizadas, as metodologias ativas no ensino de Ciências pelos professores da cidade de Angical - PI e qual o impacto que ela causa na aprendizagem dos alunos.

\section{Metodologia}

\section{Abordagem da pesquisa}

$\mathrm{O}$ presente artigo trata-se de um estudo qualitativo para investigação de metodologias com base no recolhimento de dados, afim de qualificar o ensino de Ciências da Natureza em escolas de Angical do Piauí. O mesmo baseia-se em 
informações contidas e artigos científicos, em paramentos legais como BNCC (Base Nacional Comum Curricular), LDB (Lei de diretrizes e bases), Diretrizes e Parâmetros Curriculares, e em pesquisa de campo por meio de questionários.

A realização dessa pesquisa ocorreu somente após a submissão ao Comitê de Ética em Pesquisa do Instituto Federal do Piauí CEP/IFPI, em que obteve êxito e foi aprovada (Número do Parecer: 4.552.909) em termos éticos. E então, partiu-se para aplicação após todos os participantes pesquisados concordarem com o Termo de Consentimento Livre e Esclarecido, e após assiná-lo, os dados foram recolhidos.

Foi realizada uma pesquisa de campo que conforme Gil (2008), procura o aprofundamento de uma realidade específica, e também é realizada por meio da observação direta das atividades do grupo estudado e de entrevistas com informantes para apreender as explicações e interpretações do que ocorrem naquela realidade. Segundo Strauss e Corbin (2015), a pesquisa qualitativa conta basicamente com três componentes: (i) os dados, que podem vir de várias fontes como entrevistas, observações, documentos, registros e gravações; (ii) os procedimentos, que podem ser utilizados para interpretar e organizar os dados; e (iii) relatórios escritos e verbais, que podem ser apresentados em artigos, palestras, e/ou livros.

\section{Amostragem}

Foi realizada uma pesquisa de campo por meio de aplicação de um questionário sobre metodologias existentes e aplicadas em sala de aula, direcionado a professores de Ciências da Natureza. As duas escolas públicas se localizam em Angical do Piauí, zona urbana e zona rural. Foram restritas a professores das séries de $6^{\circ}$ a $9^{\circ}$ ano.

Os dados foram produzidos por meio de questionários online - Google Forms/impressos. A análise de dados foi realizada através de um estudo basicamente descritiva dos dados coletados pelos questionários aplicados e os resultados foram confrontados com a bibliografia que trata sobre o assunto objeto desta pesquisa. O material coletado através dos questionários, após análise mais detalhada, foi categorizado e discutido.

Os dados obtidos por meio do questionário foram tabulados e organizados de forma autoexplicativa de acordo com os objetivos estabelecidos pelo estudo. Esses dados foram colocados em gráficos que facilitaram a compreensão dos achados, construídos através dos softwares Microsoft Office Excel e Microsoft Word versão 2013.

\section{Resultados e Discussão}

Os professores participantes da pesquisa foram seis, sendo três do sexo feminino e três do sexo masculino. Além disso, a escola CETI Demerval Lobão possui o maior número de professores dessa área - quatro professores -, e a Escola Átila Lira possui dois professores. Em relação às turmas contempladas, dois professores lecionam nos Anos Iniciais do Ensino Fundamental II e quatro professores lecionam nos Anos Finais do Ensino Fundamental II.

Quanto à formação dos seis professores pesquisados, apenas dois não possuem formação na área de Ciências, lecionando, essa unidade curricular apenas para suprir a necessidade do quadro de professores, no qual está faltando professores com formação específica e igual à área em que ministra as aulas. No entanto, os dois professores que não possuem o curso de Licenciatura em Ciências afirmaram que possuem outros tipos de formações que lhes garante condições de lecionar a matéria normalmente, como por exemplo, cursos de extensão e formação em Licenciatura em Biologia, por exemplo. O Gráfico 1 a seguir, demonstra esses resultados: 
Gráfico 1: Área de formação dos professores analisados.

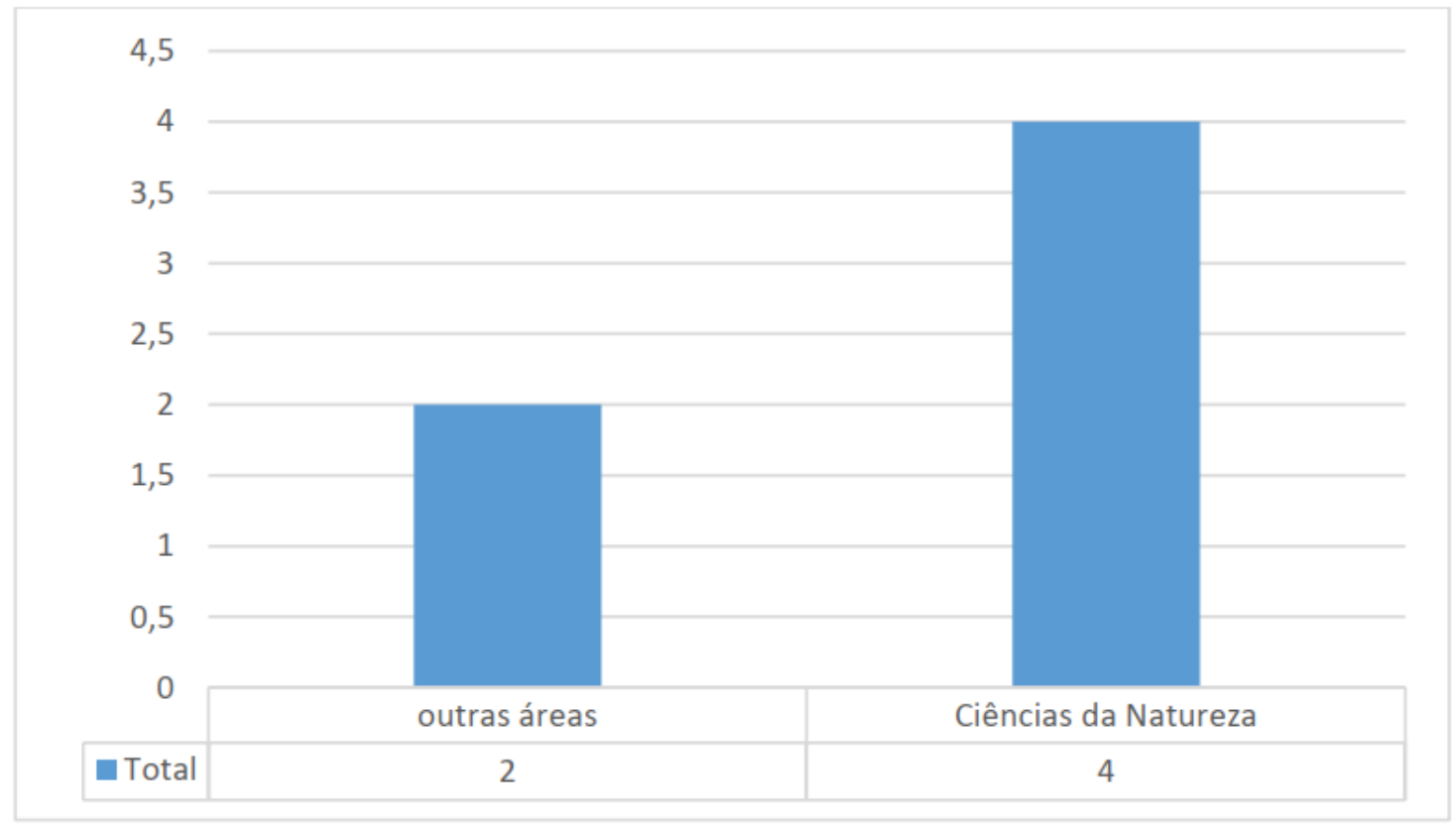

Fonte: Autores (2021).

Isso mostra que, apesar da importância do professor ter a formação na área em que trabalha não há esse cuidado nas lotações dos docentes, colocando-os para ministrar aulas em áreas diferentes de sua formação o que poderia causar alguma dificuldade para alguns profissionais por não ter o conhecimento necessário e específico da área e/ou componente curricular.

Ao serem indagados se fazem algum tipo de formação continuada, três dos professores responderam que no momento não estão realizando nenhum tipo de aperfeiçoamento, sendo que um relatou que já fez uma pós-graduação. Os outros três pesquisados responderam que atualmente fazem e que sempre buscam cursos de formação continuada e aperfeiçoamento, sejam eles pós-graduações, cursos de extensão, minicursos, e mentorias que diversas vezes são oferecidos pelos próprios contratantes.

A formação continuada é um diferencial de sumária importância na realização do trabalho de qualquer docente, pois além de ter oportunidade de se atualizar quanto profissional é um dos fatores principais capazes de contribuir e, dessa forma, garantir o sucesso em sua carreira profissional. Além disso, é importante também frisar que os alunos no ambiente escolar também serão extremamente beneficiados com as novas técnicas e práticas pedagógicas que serão utilizadas pelos professores. É importante também ressaltar que a formação continuada possa estar aliada à vontade do professor de querer realizar um trabalho pedagógico de qualidade, já que a capacitação tem o objetivo de trazer novos conhecimentos, novos conceitos, novas técnicas e práticas cotidianas no contexto escolar (Togashi, Silva, Schimer. 2017).

Os autores Blaszko, Ujiie e Carletto (2014, p. 154) propõem que "[...] independentemente do nível de ensino, da educação infantil ao ensino superior, o professor deve ser um sujeito com formação ampla e suficiente, tendo em vista promover a ação educacional qualificada". Essa afirmação reforça ainda mais a exigência que o docente busque novas metodologias, novos conhecimentos e redefine suas práticas, para que a curiosidade dos alunos, o conhecimento precedente e compreensões, bem como as representações que eles possuem sirvam de alicerce para a construção dos conhecimentos científicos.

Quanto ao uso de metodologias ativas, apenas um dos seis professores entrevistados respondeu que não as utiliza, complementando que não as conhece e, portanto, não possui a segurança necessária para utilizá-la diariamente em suas aulas. 
Na utilização de alguma metodologia ativa, é possível perceber que o estudante se torna protagonista, sendo capaz de resolver problemas e até mesmo enfrentar situações reais, desenvolver projetos, criar novas oportunidades construindo, dessa forma, novos conhecimentos, bem como um pensamento crítico e reflexivo (Farias, Martin, Cristo 2015). O Gráfico 2 expressa a utilização de metodologias ativas pelos professores entrevistados.

Gráfico 2: Uso de alguma metodologia ativa nas aulas de Ciências.

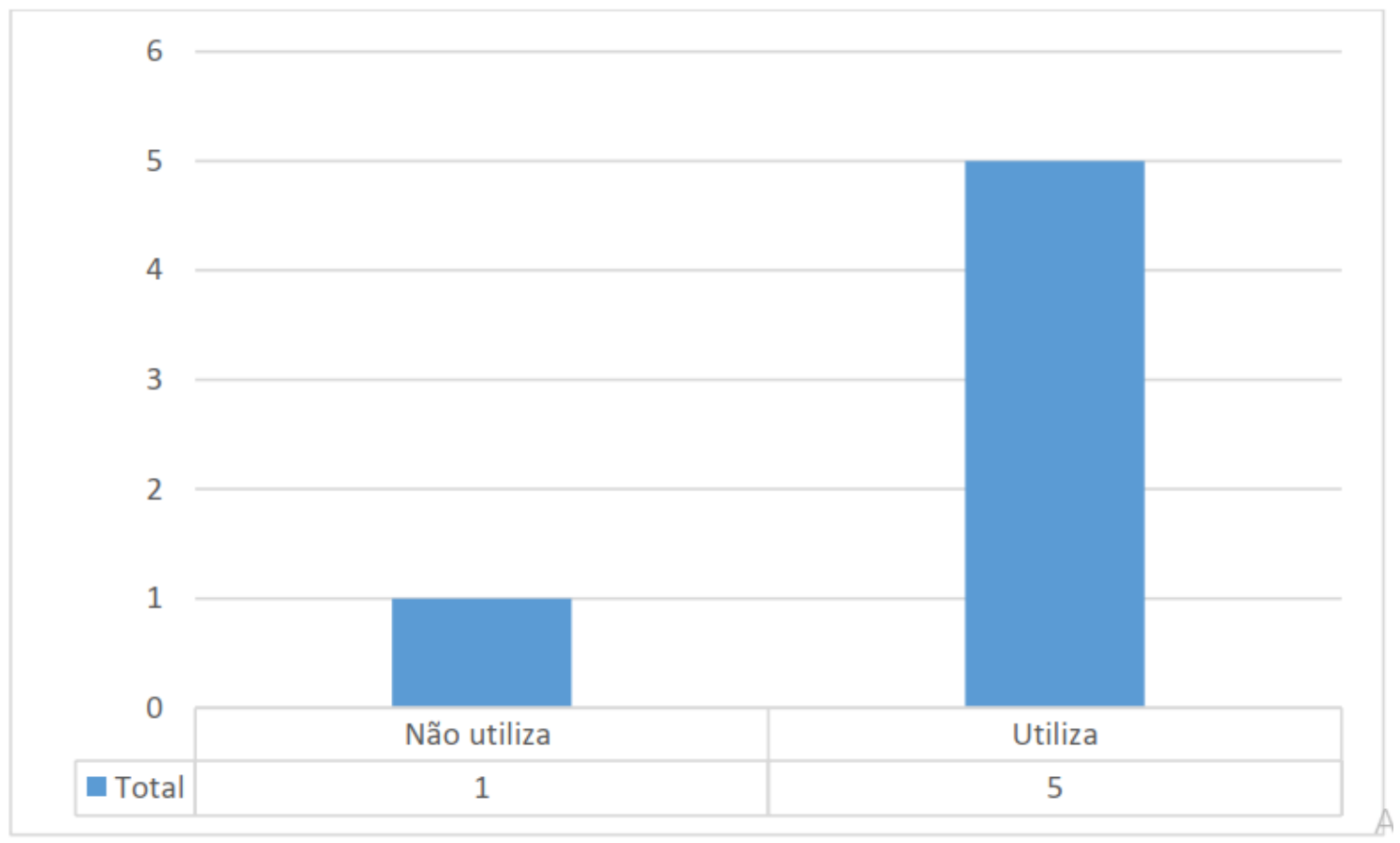

Fonte: Autores (2021).

Ao serem indagados quanto à utilização de algum tipo de tecnologia durante as aulas de ciências, todos responderam que utilizam alguma ferramenta, entre elas: o computador, o smartphone e o Datashow (apresentação em slides). Eles completaram suas respostas explicando que até mesmo pelo momento em que a educação, está passando, cujas metodologias tiveram que ser readaptadas por conta pandemia que causou uma grave crise sanitária, obrigando as escolas a adotarem a Educação à Distância, o famoso EAD, o uso do computador para transmissão das aulas foi o principal meio de aplicação das aulas. Segue abaixo as respostas dos professores sobre a utilização de tecnologia nas suas aulas:

Professor 01: "Computador nesse periodo de pandemia”

Professor 02: "Computador para gravar as vídeo aulas que ministro e utilizo também o smartphone"

Professor 03: "Utilizo apenas o celular por causa da pandemia, pois não conheço muito tecnologias e nem tenho segurança para usar"

Professor 04: "Utilizo o Datashow e smartphone"

Professor 05: "Datashow e notebook"

Professor 06: "Projetor de imagem, internet e smartphone para preparar as aulas nessa pandemia

Mesmo sem conhecer muito bem as metodologias ativas eles utilizam algum tipo de tecnologia por causa do novo formato de aulas que está sendo adotado por conta da pandemia mundial que está afetando e mudando a maneira, de forma 
radical, de ministrar as aulas atualmente. Dessa forma, o ensino nas escolas participantes da pesquisa está ocorrendo de maneira remota, predominando uma adaptação temporária das metodologias utilizadas no regime presencial, com as aulas, sendo realizadas nos mesmos horários e com os professores responsáveis pelas disciplinas dos cursos presenciais, como dito anteriormente conforme Alves (2020, p.11).

Destaca-se que a organização das metodologias de aprendizagem deve contemplar: os objetivos a atingir, conteúdos a trabalhar, a estrutura de desenvolvimento desse trabalho e procedimentos para avaliação de resultados (Silva \& Scapin, 2011). Nota-se que esse processo exige mudança de postura do professor, que está acostumado a atuar na posição tradicional de ensinar. O cenário da educação vem sofrendo grandes transformações nas últimas décadas, em especial, as concepções e técnicas de ensino têm sido questionadas. Assim, são elaboradas novas compreensões de ensino e propostas alternativas para sua operacionalização, entre elas, as denominadas metodologias ativas de ensino-aprendizagem. Estas rompem com o modelo tradicional de ensino e fundamentam-se em uma pedagogia problematizada, onde o aluno é estimulado a assumir uma postura ativa em seu processo de aprender, buscando a autonomia do educando e a aprendizagem significativa (Paiva, Parente, Brandão \& Queiroz. 2016).

O professor que trabalha com Ciências no Ensino Fundamental tem uma grande responsabilidade nas mãos, pois, ele precisa atrair a atenção dos alunos aos conteúdos que pretende ministrar em aula. O professor pode despertar a curiosidade do aluno para uma situação-problema, em que ele será o responsável pelas respostas da situação, de forma que ele se sinta estimulado a procurar uma explicação científica para esclarecer determinado conceito ou fenômeno científico. Isso faz com que a leitura e a escrita se desenvolvam - fatores importantes não só para o estudo de Ciências, mas para todas as áreas do conhecimento Louredo, 2020.

O professor 01 ao responder o questionário considera o livro como orientador e ressaltou que as vezes é o único meio de estudo do educando. Frisa ainda que, em meio a pandemia e estudos em EAD, há uma grave realidade escancarada que ainda há muita exclusão digital, que muitos estudantes não possuem meios tecnológicos para ter acesso às aulas que estão sendo realizadas de maneira remota em boa parte das escolas. Isso reforça ainda mais as respostas dos professores quanto à importância do livro didático. O segundo pesquisado (professor 02) chamou o livro didático de "guia base" para o aprendizado do aluno e esse deve ser utilizado em conjunto com as pesquisas para dar mais significado ao aprendizado. A seguir, as palavras dos professores quanto à utilização do livro didático:

"O livro orienta o professor no currículo e às vezes, é o único meio de estudo do educando" Professor 01.

"O livro é um guia base para o aprendizado do aluno, deve ser utilizado em conjunto com pesquisas para dar mais significado ao aprendizado Professor 02.

"O livro didático é um instrumento para abrir a mente dos alunos para buscar conhecimento" Professor 03.

"O livro é um material de apoio e que o aluno utiliza como fontes de pesquisa" Professor 04.

"O livro serve para a prática docente e ele contribui com informações sobre a dinâmica e as relações que os seres vivos estabelecem com o meio ambiente" Professor 05.

"O livro didático auxilia nas delimitações de informações específicas voltadas para as habilidades a serem desenvolvidas a partir do uso complementar" Professor 06.

Como se pode observar, o livro didático ainda é uma das principais ferramentas para a preparação das aulas, sendo muitas vezes, a primeira e principal fonte de pesquisa. Isso pode estar relacionado ao acesso ao livro didático por ser mais fácil e, também, por ele estar presente há muito tempo na cultura escolar. Acrescenta-se ainda o fato de os alunos também receberem um exemplar adotado como única fonte de pesquisa, preferindo segui-lo à risca. Logo se pode afirmar que o livro 
didático tem grande importância na construção do conhecimento, pois ele possui um relevante e fundamental papel na busca de informações para complementar a aula em si como fonte de pesquisa.

É importante lembrar que segundo Rosa e Artuso (2019), a maior parte das escolas que utilizam o livro didático como ferramenta pedagógica principal, são escolas que não possuem estruturas necessárias para a realização de aulas práticas com recursos tecnológicos, por exemplo. Em grande parte, são escolas que pertencem a zona rural, onde os recursos tecnológicos como aparelhos multimídia (Datashow, tablets, etc.), computadores e principalmente os laboratórios de Ciências não são uma realidade na escola, o que torna o uso do livro didático ainda mais presente. Quanto à opinião sobre a utilização de metodologias ativas nas atividades práticas como sendo um diferencial para os alunos absorverem o conteúdo, todos os professores foram unânimes, respondendo que sim. Entre as justificativas dadas pelos pesquisados sobre as metodologias ativas estão:

"Metodologias ativas são essenciais, porém nessa pandemia não é possível aplicar a todos os alunos, pois apenas alguns possuem acesso à internet, e outros ficam de fora por não terem esse acesso" Professor 01.

"Com certeza elas são um diferencial positivo, pois com as metodologias ativas o aluno é o construtor do seu próprio conhecimento" Professor 02.

"Tornar o aluno ativo no processo de ensino-aprendizagem contribui para o seu desenvolvimento na construção da aprendizagem" Professor 03.

As metodologias ativas, mesmo sem todos terem conhecimento sobre elas de forma mais profunda, é considerada um diferencial pelo fato de elas ajudarem a instigar o aluno a ser mais proativo nas aulas. Isso faz com que, em grande parte, os alunos tenham mais interesse nas aulas, transformando-se em verdadeiros protagonistas na criação do próprio conhecimento.

Ao ocorrer tantas mudanças sociais registradas nas últimas décadas, pode-se afirmar que a escola também passa por uma mudança em seu modelo educacional e assim é necessária a adaptação frente a essas mudanças. Tal dinâmica entre os estudantes, que não ficam restritos a um mesmo lugar, e sim, conectados e imersos a uma significativa gama de informações que se transformam de forma contínua, trazendo à tona o papel do aluno como protagonista do conhecimento e as metodologias ativas possuem um papel importantíssimo nesse novo modelo educacional (Diesel, Baldez, e González. 2017).

Em relação às possíveis dificuldades enfrentadas pelos professores que participaram dessa pesquisa estão, em suma, a questão da pandemia enfrentada atualmente que prejudica ainda mais o acompanhamento mais preciso de cada aluno, bem como o acesso à internet que é muitíssimo limitado. Entretanto, afirmaram que mesmo antes da pandemia já havia diversas dificuldades a serem enfrentadas, porém com características diferentes das atuais, cabendo aqui citar: a falta de interesse do alunado e participação dos mesmos no processo de ensino-aprendizagem, o acesso à internet; a falta de engajamento de alunos e familiares no processo de acompanhamentos das atividades; atualização dos conhecimentos para o uso das novas tecnologias para depois conseguir aplica-las; falta de recursos, infraestrutura adequada para o desenvolvimento de atividades críticas/reflexivas; e, por fim, a falta de conhecimento da parte de alguns professores (não conhecem ou simplesmente preferem continuar no comodismo de não elaborar aulas dinâmicas e práticas). Abaixo, nas palavras dos professores pesquisados, o relato das principais dificuldades enfrentadas:

"O interesse do alunado, deve partir dele a vontade de aprender, uma vez que o professor faz o intermédio entre o conteúdo do aprendizado e o aluno" (Professor 01).

"A falta de participação dos alunos, a dificuldade de acesso de parte dos alunos a internet, a falta de interesse e etc." (Professor 02).

"Atualizar os conhecimentos para as tecnologias" (Professor 03).

“Conseguir praticá-las" (Professor 04). 
"Falta de recursos e, às vezes, infraestrutura adequada para o desenvolvimento de atividades críticas/reflexivas" (Professor 05).

"A maioria dos professores podemos perceber que ainda não conhecem ou simplesmente preferem continuar no comodismo de não elaborar aulas dinâmicas e práticas" (Professor 06).

Essas dificuldades são um entrave para o uso de metodologias ativas, pois para que se possa utilizá-las são necessários recursos tecnológicos disponíveis, atualização do conhecimento e infraestrutura. No entanto, é indispensável que haja também motivação em aprender novos métodos, novas didáticas e novas formas de atrair os alunos. Essa necessidade é importante, pois cada vez mais há mudanças no cotidiano e na cultura da sociedade e os professores precisam estar atentos a essas dinâmicas para que assim façam um trabalho mais atraente e eficaz.

Além disso, Diesel, Baldez e Martins (2017) afirma que o contexto social no qual a escola está inserida é um dos pontos principais que podem dificultar a prática das metodologias ativas, evidenciando a histórica dicotomia entre teoria e prática, podendo protagonizar uma das causas de desmotivação, desinteresse e apatia dos estudantes. Isso reflete também na estrutura oferecida pelo ambiente escolar como um todo e reforça a ideia de que tais metodologias precisam focar na realidade desse aluno, tendo que ser útil para a vida, com grande probabilidade de aplicação na prática e que deve favorecer o desenvolvimento crítico e articulado do conhecimento. O método ativo é constituído de processos educativos que visam estimular uma aprendizagem crítica e reflexiva, em que o estudante possui papel ativo e é corresponsável pelo seu próprio aprendizado.

Em relação a maior dificuldade ao planejar aulas de Ciências da Natureza, o gráfico abaixo mostra que três dos professores pesquisados responderam que a maior dificuldade dentre as alternativas do questionário é o acervo tecnológico e impresso escolar são incompatíveis com a necessidade das aulas de Ciências da natureza. Outro pesquisado, afirmou que o maior desafio é a dificuldade de reter a atenção do aluno. Finalmente, o último entrevistado respondeu que a maior dificuldade para o planejamento das aulas é que alguns instrumentos/materiais seriam necessários para melhor realizar a aula planejada visto que ainda estamos lidando com uma precária realidade de condições de trabalho não favoráveis, principalmente para o ensino de Ciências. Nenhum dos professores marcaram as alternativas a (Falta de formação) e b (Pouco tempo que a Escola disponibiliza para professor (a) no planejamento da disciplina) do questionário.

Gráfico 3: Dificuldade no planejamento da disciplina de Ciências da Natureza.

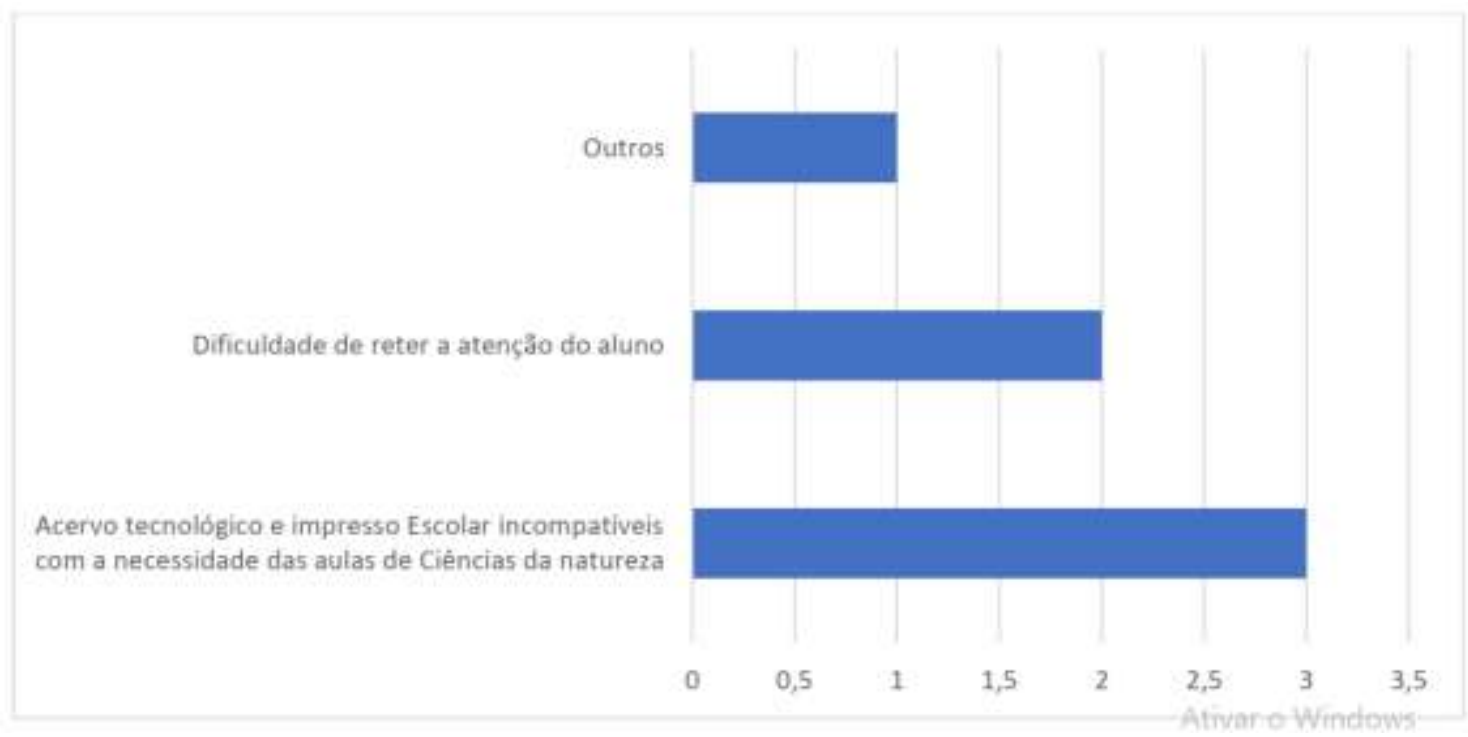

Fonte: Autores (2021). 
O Gráfico 3 mostra que as dificuldades no planejamento das aulas estão intimamente ligadas a capacidade da escola em termos de recursos e infraestrutura disponíveis para os docentes planejarem e executarem as aulas de ciências de forma mais plena. É valido afirmar que a dificuldade de reter a atenção dos alunos está relacionada às aulas maçantes que não condizem com o perfil dessa geração atual, que está atraída por tecnologia e aulas que envolvam o contexto em que vivem.

O professor precisa refletir sobre sua função para não deixá-la limitada, pois essa reflexão impacta diretamente no aprendizado dos alunos. O professor que não alcança seu próprio aprendizado terá dificuldades em construir conhecimentos com os alunos e, consequentemente, a apropriação do assunto será restrita. É importante que o professor pesquise sobre os conteúdos de sua pasta, reveja cada aula, cada unidade didática e repense sobre os pontos que poderão reduzir tais dificuldades e descobrir alguns pontos que possam ter ficado pendentes no planejamento das aulas. Tais variáveis podem contribuir na sua prática e organização de seu plano (Trevisan, Antunes e Gonzáles. 2017).

Assim, os resultados apresentados nesse trabalho são considerados importantes, visto que demonstrou que em meio a um período da história em que a tecnologia tornou-se uma ferramenta de grande destaque para as metodologias ativas na educação ainda há muitas dificuldades em utilizá-la de forma plena. Tais problemas estão relacionados tanto à estrutura oferecida aos docentes quanto a formação e aperfeiçoamento deste, os quais são imprescindíveis ao ensino de Ciências, que necessita, em grande parte, de atualização constante bem como uma estrutura. Até o momento, poucos estudos foram reportados sobre as metodologias ativas no ensino de ciências no Estado e na região do presente estudo, o que reforça ainda a importância desta pesquisa.

\section{Conclusão}

A partir da avaliação das metodologias existentes e aplicadas em sala de aula, pelos professores de Ciências da cidade de Angical - PI, foi possível observar que ainda há grande dificuldade de implantação de aulas mais dinâmicas utilizando-se as metodologias ativas, mostrando até mesmo que há, ainda, professor que não conhece tais conceitos para poder aplicá-los em sala de aula. Além disso, demonstrou-se também que há uma falta de motivação por parte dos professores, haja vista que, apesar da maioria conhecer as metodologias ativas, não se tem interesse em sua execução nas aulas, por falta de motivação, de recursos, apoio pedagógico e, principalmente, por acharem que os alunos não possuem o interesse necessário, desmotivando os professores ainda mais.

Dessa forma, foi possível perceber a necessidade de alguns professores conhecerem as metodologias ativas de forma a obter maior proveito delas e também de obter recursos disponíveis para utilizá-las com maior eficiência. Isso também somado à mudança do olhar metodológico na execução das aulas e até mesmo, na curiosidade de conhecer mais ferramentas e metodologias ativas diferentes, apesar de haver grandes desafios em executá-las em salas de aula.

Como sugestão a novas pesquisas, pode-se sugerir a mudança do público pesquisado: ao invés de aplicar a pesquisa com os professores, aplicar com os alunos. Isso mostraria possíveis motivos da "falta de interesse" citada pelos professores e, principalmente, demonstraria o que poderia ser feito para estimular, instigar e atrair a atenção desses alunos nas aulas, fixando ainda mais o conhecimento proporcionado em aula.

\section{Referências}

Alves, L. (2020). Educação remota: entre a ilusão e a realidade. Interfaces Científicas, 8(3), 348 - 365 . https://periodicos.set.edu.br/educacao/articl e/download/9251/4047

Barbosa, E. F., \& de Moura, D. G. (2013). Metodologias ativas de aprendizagem na educação profissional e tecnológica. Boletim Técnico do Senac, 39(2), 4867. https://bts.senac.br/bts/article/view/349

Basílio, J. C., \& Oliveira, J. C. (2016). Metodologias Ativas para o aprendizado de Ciências Naturais no Ensino Básico. 
Blaszko, C. E., Ujie, N. T., \& Carletto, M. R. (2014) Ensino de ciências na primeira infância: aspectos a considerar e elementos para a ação pedagógica. In: UJIIE, Nájela Tavares, PIETROBON, Sandra Regina Gardacho. Educação, infância e formação: vicissitudes e quefazeres. Curitiba: CRV, p. $151-168$.

Diesel, A., Baldez, A. L. S., \& Martins, S. N. (2017). Os princípios das metodologias ativas de ensino: uma abordagem teórica. Revista Thema, 14(1), 268-288 https://edisciplinas.usp.br/pluginfile.php/4650060/mod_resource/content/1/404-1658-1-PB\%20\%281\%29.pdf

Faria, P. A. M. de., Martin, A. L. A. R., \&Cristo, C. S. (2015). Aprendizagem Ativa na Educação em Saúde: Percurso Histórico e Aplicações. Revista Brasileira de Educação Médica. 39(1), 143-150 https://www.scielo.br/scielo.php?pid=S0100 55022015000100143\&script=sci_abstract\&tlng=pt

FREITAG, I. H. (2017). A importância dos recursos didáticos para o processo ensino-aprendizagem. Arquivos do MUDI, 21(2), 20-31. https://periodicos.uem.br/ojs/index.php/ArqMudi/article/view/38176https://periodicos.uem.br/ojs/index.php/ArqMudi/article/view/38176.

Gil, A. C. (2008) Como elaborar projetos de pesquisa. (4a ed.), Atlas.

Gonçalves, A. S., Silva, M. R. Q., Inácio, W. P., \& Alves, F. C. (2018). Metodologias utilizadas por professores do ensino fundamental nas aulas de ciências naturais, Anais.Editora Realize, VII ENALIC. https://www.editorarealize.com.br/editora/anais/enalic/2018/443-55751-28112018-230620.pdf.

Lara E.M. O., Lima V.V., Mendes, J. D., Ribeiro, E. C. O., \& Padilha, R. Q. (2019). O professor nas metodologias ativas e as nuances entre ensinar e aprender: desafios e possibilidades. Interface. 23: e180393. https://doi.org/10.1590/Interface.180393.

Louredo, P. (2020). Ensino De Ciências.Brasil Escola: Orientações. https://educador.brasilescola.uol.com.br/orientacoes/ensino-ciencias.htm

Martins, O. A. da S., Silva, M. R., \& Almeida, V. de S. (2021). Sala de Aula Invertida: Uma metodologia Ativa na Aprendizagem. Ensino Em Perspectivas, 2(2), 1-5. https://revistas.uece.br/index.php/ensinoemperspectivas/article/view/5701

Melo, J. R. de. (2013). Análise do perfil dos professores de Ciências Naturais dos Anos Iniciais do Ensino Fundamental: um estudo nas Escolas de Planaltina DF. Universidade de Brasília, UNB Planaltina. Trabalho de Conclusão de Curso, https://bdm.unb.br/bitstream/10483/5898/1/2013_JeniferRicardaDeMelo.pdf.

Morán, J. (2015). Mudando a educação com metodologias ativas. Coleção mídias contemporâneas. Convergências midiáticas, educação e cidadania: aproximações jovens, 2(1), 15-33. https://edisciplinas.usp.br/pluginfile.php/4941832/mod_resource/content/1/Artigo-Moran.pdf

Oliveira, J. K. C. DE, Pimentel, F. S. C. (2020). Epistemologias da gamificação na educação: teorias de aprendizagem em evidênciA. Revista da FAEEBA Educação e Contemporaneidade, 29(57), 236-250. https://www.revistas.uneb.br/index.php/faeeba/article/view/8286 Acesso 02 de abril 2020.

Oliveira, L. de, \& Neiman, Z. (2020). Educação Ambiental no Âmbito Escolar: Análise do Processo de Elaboração e Aprovação da Base Nacional Comum Curricular (BNCC). Revista Brasileira De Educação Ambiental (RevBEA), 15(3), 36-52. https://doi.org/10.34024/revbea.2020.v15.10474

Silva, R. H. A., \& Scapin, L. T. (2011). Utilização da avaliação formativa para a implementação da problematização como método ativo de ensinoaprendizagem. Est. Aval. Educ., 22(50), 537-552.

Strauss, A., \& Corbin, J. (2015) Basics of qualitative research: techniques and procedures for developing Grounded Theory.California: SAGE. https://www.metodologiacientifica.org/tipos-de-pesquisa/pesquisa-teoriafundamentada-grounded-theory/

Paiva, M. R., Parente, J. R. F., Brandão, I. R., \& Queiroz, A. H. B. (2016). Metodologias ativas de ensino-aprendizagem: Revisão interativa. SANARE, Sobral - 15(2), 145-153. https://sanare.emnuvens.com.br/sanare/article/view/1049/595

Rosa, D. A. M., \& Artuso, A. R. (2019). O Uso do Livro Didático de Ciências de $6^{\circ}$ a $9^{\circ}$ Ano: Um Estudo com Professores Brasileiros. Revista Brasileira De Pesquisa Em Educação Em Ciências, 709-746. https://doi.org/10.28976/1984-2686rbpec2019u709746

Togashi, C. M., Silva, T. M., \& Schimer, C. R. (2017). A importância da formação continuada para ampliar os conhecimentos dos professores do Atendimento Educacional Especializado em Comunicação Alternativa e Ampliada. In: NUNES, L. R. O. P., and SCHIRMER, C. R., orgs. Salas abertas: formação de professores e práticas pedagógicas em comunicação alternativa e ampliada nas salas de recurso multifuncionais. EDUERJ, 169-176. http://books.scielo.org/id/xns62/epub/nunes-9788575114520.

Trevisan, K. I., Antunes, F. R. I., \& Gonzàlez, F. J. (2017). Fatores que interferem no planejamento escolar: dificuldades de uma docente da rede básica de ensino. Trabalho vinculado ao projeto Transformação da Educação Física Escolar. Limites e Potencialidades de experiências colaborativas de Formação Continuada Grupo Paidotribas da Unijuí. Salão do Conhecimento, 2017. file:///C:/Users/iara/Downloads/7961Texto\%20do\%20artigo-34057-1-1020170918.pdf 